\title{
A ANIMAÇÃO COMO OPÇÃO TECNOESTÉTICA EM VINHETAS DE ABERTURA DE FILMES
}

\author{
Denise Guimarães ${ }^{1}$
}

\begin{abstract}
Resumo: Este artigo busca uma possível (re)articulação das questões ligadas à representação e aponta a importância de se considerar como os regimes de visualidade são alterados, por força dos efeitos tecnoestéticos na linguagem das novas mídias. São analisados os signos intercambiantes entre o verbal e o icônico, em vinhetas de abertura de filmes, com base nos conceitos teóricos fundamentais de Charles Sanders Peirce. Uma leitura intersemiótica investiga práticas criativas que integram signos visuais e verbais, os quais implicam um desafio estético, partindo da animação para as imagens computadorizadas. Há ainda uma referência às questões formuladas por Lev Manovich e por Wiliam Brown sobre o que acontece com a identidade indicial do cinema, quando a tecnologia fílmica tradicional vem sendo substituída pela tecnologia digital.
\end{abstract}

Palavras-chave: Vinhetas de abertura, cinema, animação, tecnologia digital.

Abstract: This article looks for a possible (re)articulation of questions linked to representation and enphasizes the importance of considering how visuality regimes are altered, due to techno-aesthetic devices in the language of new media. Are analyzed the interchangeable signs between the verbal and the iconic, in cinematographic soap opera openings, based on fundamental Charles Sanders Peirce's theoretical concepts. An intersemiotic reading investigates creative practices that integrate visual and verbal signs, which implies an aesthetic challenge, from animation to computer images. There is also an reference to Lev Manovich's and Wiliam Brown's questions about what happens to cinema's indexical identity, when traditional film technology is being replaced by digital technology.

Keywords: Soap Opera Openings, cinema, animation, digital technology.

\section{Introdução}

Este artigo procura uma possível (re)articulação das questões ligadas à representação, com aporte na semiótica de Charles Sanders Peirce (1839-1914); sua ênfase recai na importância de como os regimes de visualidade são alterados, em virtude dos dispositivos utilizados a cada momento histórico. São objetos empíricos deste estudo três vinhetas de abertura de filmes, que fazem uso da animação como opção tecnoestética. A escolha do referido tema deve-se, sobretudo, à assertiva de Lev Manovich (2001), assumidamente leitor de Peirce, que o cinema, tendo nascido da animação, relegou-a a um plano inferior durante todo o século XX, para, finalmente tornar-se ele mesmo um caso especial de animação, na era digital. A inquietação sígnica que serve de ponto de partida para minhas reflexões é o questionamento do referido pesquisador sobre a identidade indicial do cinema:

\footnotetext{
${ }^{1}$ Doutora em Estudos Literários pela Universidade Federal do Paraná. Docente, orientadora e pesquisadora do Doutorado e Mestrado em Comunicação e Linguagens da Universidade Tuiuti do Paraná. Editora Científica da Revista Interin. E-mail: denise.guimaraes@utp.br.
} 
Mas o que acontece à identidade indexical do cinema usando 3-D se agora é possível gerar cenas foto realistas inteiramente em um computador usando animação computadorizada 3-D; para modificar frames ou cenas inteiras com o auxílio de programa de pintura digital; para cortar, dobrar, esticar e pontuar imagens fílmicas digitalizadas em algo que tem perfeita credibilidade fotográfica, embora nunca tenha sido realmente filmado? (MANOVICH, 2001, p. 295). ${ }^{2}$

Após desenvolver sua argumentação sobre as mudanças no processo de filmagem na história das imagens em movimento, o autor enfatiza:

\begin{abstract}
Visto neste contexto, a construção manual de imagens no cinema digital representa um retorno às práticas pro-cinemáticas do século dezenove, quando imagens eram pintadas a mão e animadas a mão. [...] Consequentemente, o cinema não pode mais ser claramente diferenciado da animação. Essa é não mais uma mídia indexical tecnológica mas, sim, um subgênero da pintura. (MANOVICH, 2001, p. 295). ${ }^{3}$
\end{abstract}

William Brown (2015) também inicia sua filosófica exploração do cinema digital, retomando o debate sobre a indicialidade e exemplifica com a cena de abertura do filme $O$ Clube da Luta (1999), dirigido por David Fincher:

Eu devo indagar sobre o realismo nas tomadas de abertura de Clube da Luta, mas para fazê-lo devo estabelecer o que o realismo cinematográfico é ou deve significar. Há inúmeros níveis concorrentes em que um filme pode ser considerado realista [...] $\mathrm{Eu}$ devo questionar isso apesar da objeção comum que as imagens geradas por computador não são indicialmente reais. De fato, eu devo indagar se a questão da indicialidade dominou indevidamente o discurso que envolve o cinema digital. (BROWN, 2015, p. 22). ${ }^{4}$

\footnotetext{
${ }^{2}$ No original: But what happens to cinema's indexical identity if it is now possible to generate photorealistic scenes entirely in a computer using 3-D computer animation; to modify individual frames or whole scenes with the help a digital paint program; to cut, bend, stretch and stitch digitized film images into something which has perfect photographic credibility, although it was never actually filmed?

${ }^{3}$ No original: Seen in this context, the manual construction of images in digital cinema represents a return to the pro-cinematic practices of the nineteenth century, when images were hand-painted and hand-animating. [...] Consequently, cinema can no longer be clearly distinguished from animation. It is no longer an indexical media technology but, rather, a subgenre of painting.

${ }^{4}$ No original: I shall argue for the realism of the opening shots of Fight Club, but in order to do so I must establish what cinematic realism is or might mean. There are several competing levels at which a film might be deemed realistic [...] I shall argue this in spite of the common objection that computer generated images are not indexically real. Indeed, I shall argue the question of indexicability has unduly dominated discourse surrouding digital cinema.
} 
O autor apresenta diversos exemplos de filmes que corroboram sua argumentação, na contraposição entre imagens analógicas e digitais, para enfatizar que a emancipação dos limites da indicialidade e da materialidade são fatores intrínsecos e imanentes ao cinema digital, por ele denominado supercinema.

Tais reflexões levam-me à escolha do corpus empírico para análise, constituído por três vinhetas cinematográficas que exploram o gênero animação em diferentes técnicas: o curta metragem animado de Saul Bass que abre a comédia It's a Mad Mad Mad Mad World (1963), dirigida por Stanley Kramer; a sequência inicial criada por Peter Lamont para o filme Casino Royale (2006), dirigido por Martin Campbell; e a abertura elaborada por Steve Saklad para o filme Juno (2007), de Jason Reitman.

Enquanto a abordagem da primeira peça analisada - considerada um exemplo paradigmático de cinco décadas atrás -, centra-se na técnica da animação tradicional; a preocupação com as neotecnologias das imagens ganha maior peso nas análises das duas aberturas seguintes, pelo fato de serem produtos da era digital, ou seja, por representarem o resultado de um processo evolutivo em direção ao hibridismo característico das novas mídias.

\section{Características (inter)sígnicas peculiares às vinhetas de abertura}

Considero que os textos teóricos de Manovich, pelo fato de irem além da simples descrição e das restrições temáticas, procuram perceber determinado espírito do tempo, viabilizando o entendimento de como as mídias digitais alteram as já existentes, de como se reorganizam e redimensionam a utilização de seu potencial. Para o autor, muito embora o conceito de multimídia tenha se tornado costumeiro e ligado aos computadores, por volta de 1990, já nessa época as obras de Peter Greenaway, por exemplo, atestam que o cinema é, desde suas origens, multimidiático.

[...] cineastas têm combinado imagens em movimento, som, e texto (desde os intertítulos da era muda ou as sequências de créditos do último período) por todo um século. O cinema foi então a moderna "multimídia" original. Podemos também apontar exemplos mais antigos de dispositivos de mídia múltipla tais como as iluminuras medievais manuscritas que combinam texto, gráficos, e imagens representacionais. (MANOVICH, 2001 p. 50). ${ }^{5}$

\footnotetext{
${ }^{5}$ No original: [...] filmakers had been combined moving images, sound, and text (whether the intertitles of the silent era or the title sequences of the later period) for a whole century. Cinema was thus the original modern 
Tem-se aí, portanto, a origem das vinhetas nos textos medievais e, posteriormente, o uso do termo nas sequências iniciais e nos intertítulos dos filmes, como ocorre até hoje. Embora de certo modo consideradas periféricas aos filmes em si, por parte dos estudos acadêmicos, acredito que as sequências de abertura são criações audiovisuais relevantes e assim, portanto, pretendo indagar sobre o que poderia fazer de uma sequência inicial algo particularmente expressivo e instigante, com seu relevo semiótico estético reconhecível como tal.

No início do século XX a linguagem cinematográfica incorporou as vinhetas, tanto para a abertura dos filmes, quanto para os cartazes/letreiros que passavam informações escritas, entre as diferentes sequências, no cinema mudo. Hoje, podemos entender a vinheta no cinema como uma espécie de embalagem do filme, um ornamento criado externamente e normalmente sem ligação direta com o seu conteúdo. Entretanto, em alguns filmes, as cenas de abertura não só se integram ao enredo e ao clima psicológico da trama, como também se revelam altamente estéticas, devido ao tratamento dado aos recursos técnicos próprios do meio.

Sidney Carlos Aznar, em estudo pioneiro sobre o tema, no Brasil, considera que as vinhetas só conseguiram transformar-se numa linguagem artística na televisão. Indubitavelmente, as vinhetas da TV representam um passo além das primeiras experiências artísticas na abertura de filmes. Como as artes gráficas passaram a trabalhar com imagens eletrônicas sintetizadas em vídeo, as vinhetas televisivas foram se tornando cada vez mais sofisticadas, como demonstra o trabalho de Hans Donner na rede Globo, que lhes impôs um padrão de excelência, com repercussões internacionais. Segundo o autor,

[...] A vinheta no cinema não se traduz como uma linguagem específica desse veículo, ao passo que na TV, ela se fez linguagem, explorando todos os recursos eletrônicos do computador, e, se isso não bastasse, apoderou-se das diferentes linguagens artísticas (musical, plástica e corporal), transformando-se numa linguagem artística do vídeo. (AZNAR, 1997, p.48).

"multimedia". We can also point to much earlier examples of multiple-media displays, such as medieval illuminated manuscripts that combine text, graphics, and representational images. 
Em termos semióticos, o mais importante é "como" o design gráfico e os elementos cinematográficos são utilizados nesse tipo de produto, além de servir para estabelecer o mood, apresentar os personagens e introduzir os temas dos filmes. Expressivas são, portanto, as negociações tecnoestéticas disponíveis a cada época; procedimentos estes que implicam uma ação significante dos criadores, ao transformarem um tipo de interação estritamente verbal em outro verbal/icônico, mas, sobretudo, visual e rítmico.

Muitas dessas escritas/escrituras audiovisuais tornam-se avessas ao controle das relações lógicas, fazendo com que sensorialidade substitua a inteligibilidade, pela força da ambiguidade e do impulso lúdico, que redimensionam a arbitrariedade do signo verbal. $\mathrm{O}$ conceito de arbitrariedade vem da obra de Ferdinand de Saussure, o criador da linguística no início do século $\mathrm{XX}$, para quem o signo verbal não é motivado (não tem relação de similaridade com o seu objeto). Portanto, é arbitrário o relacionamento entre significante (camada material do signo) e o significado (camada conceitual do signo), em virtude de seu caráter lógico e socializado. Diz o autor: “[...] podemos dizer mais simplesmente: o signo linguístico é arbitrário.” (SAUSSURE, 1971, p. 81). Contudo, no caso das vinhetas de aberturas do cinema ou da televisão, os signos intercambiantes entre o verbal e o icônico, ganham ênfase na ampliação do espaço da escrita; o que se configura como um desafio estético para a exploração motivada de formas cinéticas, das texturas e das nuances cromáticas em palavras e letras.

O primeiro inovador nas vinhetas de abertura foi George Méliès, um dos precursores do cinema, com mais de 500 filmes a partir de 1896. Ilusionista e considerado o "pai dos efeitos especiais", também foi o primeiro cineasta a usar desenhos de produção e storyboards. Foi o criador das palavras em movimento na publicidade. Tendo assistido a apresentação dos irmãos Lumière - a primeira projeção de cinema, em Paris, a 28 de dezembro de 1895 Méliès passou a desenvolver vários truques: quadro a quadro, que é a base do cinema de animação; substituição de imagens, quando uma imagem desaparece, deixando lugar a outra; o princípio da montagem e a superposição de imagens, que são as bases da grande trucagem cinematográfica. Segundo George Sadoul, foi Méliès quem “uniu pela primeira vez várias cenas teatrais ou quadros móveis, transformando o cinematógrafo em cinema." (SADOUL, 1956, p. 38). Manovich entende que, 
Conceitualmente, os gráficos fotorrrealistas computadorizados já haviam aparecido com as fotografias de Félix Nadar nos anos 1840 e certamente com os primeiros filmes de Georges Méliès nos anos 1890. [...] Ao dizê-lo, eu não nego a ingenuidade humana e a quantidade tremenda de trabalho que hoje é necessária na criação de efeitos especiais gerados por computador. (MANOVICH, 2001, p. 201). ${ }^{6}$

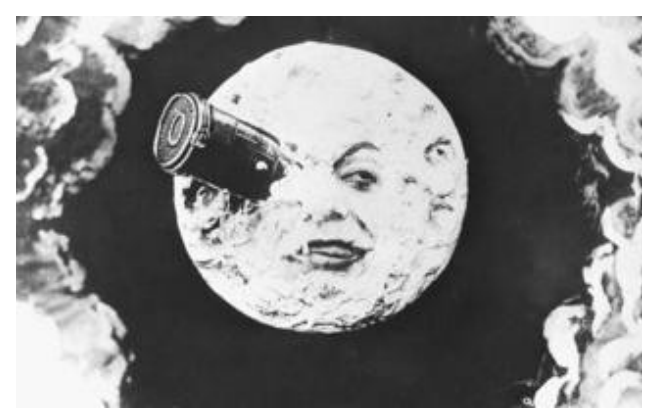

Figura 1- Frame do filme de G. Méliès (1902). ${ }^{7}$

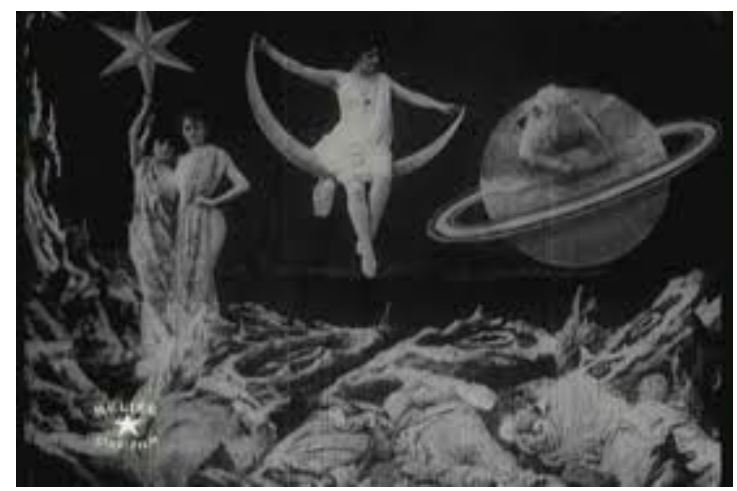

Figura 2 - Frame do filme de G. Méliès (1902).

Em seu filme de 14 minutos Le voyage dans la lune (Viagem à Lua) de 1902 considerado o primeiro filme de ficção científica -, Méliès integra inúmeras experiências ousadas com algumas técnicas cinematográficas como a sobreposição, a fusão e a exposição múltipla de imagens, valendo-se das técnicas incipientes da animação para obter efeitos especiais inovadores à época, e, também, para a apresentação e divulgação de seu filme. Outrossim, não é de hoje que o cinema utiliza-se da animação para compor as logomarcas customizadas dos grandes estúdios e distribuidoras, além de personalizar os créditos iniciais e

\footnotetext{
${ }^{6}$ No original: Conceptually, photorealistic computer graphics had already appeared with Félix Nadar's photographs in the 1840s and certainly, with the first films of Georges Méliès in the 1890's. [...] In saying this, I do not negate the human ingenuity and the tremendous amount of labor that today goes into creating computer generated special effects.

${ }^{7}$ Todos os frames foram capturados diretamente dos DVD's dos filmes, pela autora deste artigo.
} 
finais dos filmes. Trata-se de um acabamento diferenciado que permite a apresentação dos produtos da forma mais atraente possível.

Nos desenhos animados tradicionais as ações são trabalhadas quadro a quadro: para cada pequeno movimento, é preciso realizar vários desenhos. Como a nossa visão consegue distinguir até oito imagens por segundo, os desenhistas fazem, no mínimo, 12 quadros para cada segundo de animação. Um filme de uma hora tem cerca de 43.200 desenhos. Os desenhos são feitos a mão e retraçados num plástico transparente. Depois, coloca-se a célula sobre um fundo pintado e os movimentos são fotografados um a um, com uma câmara, para finalmente serem projetados em uma tela.

Embora o uso de células e de câmeras esteja em declínio devido ao avanço da animação computadorizada, as técnicas de animação e os personagens clássicos ainda servem de inspiração frequente para as novas gerações de animadores, principalmente aqueles que se assumem como experimentais. Marina Estela Graça entende que o filme animado de autor não é subserviente à fiabilidade da instrumentalidade do mecanismo que sustenta a ilusão fílmica em si, logo, assume sua crítica sistemática enquanto a delimita. Diz ela:

\footnotetext{
A posição aqui defendida é que, quando alguém faz um filme usando técnicas de animação _ e tem controle obre o resultado total _, inicia, ao mesmo tempo,um processo que inequivocamente põe em questão a inteira produção do discurso fílmico, quer no nivel dos modos de expressão, quer no nivel dos dispositivos técnicos que que o suportam, quer no nível da posição que a tecnologia ocupa nos modos de comunicação.(GRAÇA, 2006, p. 22).
}

A pesquisadora portuguesa conclui que o autor de filme animado age num contexto tecnológico completo e não procura representar qualquer outra coisa, como ocorre na representação pictórica. Ou seja, a lógica representacional é de outra ordem, consistindo em “manipulação dos modos de codificação gráfica, manipulação da composição de movimento e manipulação da continuidade descontinuidade.” (GRAÇA, 2006, p. 22). A autora afirma que “a origem referencial do filme de animação não presupõe a representação das variáveis visíveis dos objetos da realidade observável [...] como acontece com o filme fotográfico.” (GRAÇA, 2006, p. 166).

Sabe-se que o cerne da concepção da imagem fotográfica e por extensão, do cinema, no século XX é seu entendimento como índice, ou seja, como um tipo de signo que implica 
uma conexão dinâmica ao integrar uma relação efetiva com o objeto representado. Todavia, tanto na animação tradicional quanto nas mídias digitais o referido caráter indicial estaria sendo recusado em favor da percepção icônica (Peirce, 1990) ${ }^{8}$, ou seja, daquilo que diz respeito a uma qualidade e parte de uma evidência qualissígnica que emana do objeto.

\title{
3. Uma vinheta paradigmática
}

As primeiras vinhetas de abertura dos filmes norte-americanos foram realizadas por artistas gráficos que efetuaram um trabalho artístico antes desconhecido, como explica Décio Pignatari:

\begin{abstract}
Nos anos 50, particularmente no cinema americano, o espírito de inovação começou a ser observado num setor que normalmente não atrai o espectador comum - antes, costuma irritá-lo. Estou falando da apresentação do filme, dos letreiros. Foi nesse período que eles a tornaram uma verdadeira especialização, uma arte gráfica do cinema. (PIGNATARI, 1971, p. 10)
\end{abstract}

Exemplo clássico é a abertura em animação criada por Saul Bass ${ }^{9}$ para a comédia $I t ' s a$ Mad Mad Mad Mad World (Deu a louca no mundo), dirigida por Stanley Kramer (1963). Trata-se, paradoxalmente, de uma obra independente - uma espécie de desenho animado, que mantém sua inteireza semântica - mas, simultaneamente, de um produto audiovisual destinado a uma apresentação de outro, que é o filme. Assim, além de passar informações sobre os participantes da produção e contextualizar a narrativa, esta vinheta de abertura visa o maior impacto possível e poderia ser considerada uma animação de curta metragem, na qual se brinca com um globo terrestre e os créditos do filme. Julgo pertinente afirmar que a elaboração da animação de abertura do filme de Kramer revela uma postura crítica quanto à instrumentalidade do dispositivo fílmico tradicional. Aliás, consoante costuma ocorrer na elaboração dos filmes animados, a referida autora afirma que Saul Bass "Questiona os modos convencionais de construção gráfica da imagem, assumindo suas partes elementares, mas

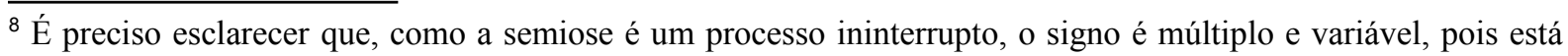
sempre em diálogo com o signo que está sendo interpretado. Desse modo, seus poderes - evocativo (icônico), indicativo (indicial) ou significativo (simbólico) não são estanques - nenhum signo pertence apenas a um tipo exclusivo. Em qualquer processo sígnico, o que ocorre é a predominância de um desses valores sobre os outros.

${ }^{9}$ Um dos primeiros designers a se destacar na tarefa de criar créditos de filmes foi o americano Saul Bass, responsável por uma nova "espécie" de vinhetas na década de 50 e 60, ele transformou os créditos em arte, suas composições serviam de prólogo para o filme, dando o tom e preparando a platéia para o que estava por vir.
} 
sujeitando-as à modelação no tempo. Assume este último como materialidade plástica, suscetível de ser modelada." (GRAÇA, 2006, p. 133)

Em termos linguísticos e semióticos, o artista opta pela força icônica dos vocábulos e fragmentos espacializados que são projetados dos cortes efetuados no globo terrestre, durante a sequência inicial do filme. Desse modo, a estaticidade dos conceitos sintagmaticamente organizados, que é própria de uma cultura alfabética linearizante, é relativizada pela possibilidade constante de movimento relacional entre elementos equivalentes, no nível do paradigma.

Os signos verbais que são símbolos, para Peirce ${ }^{10}$, saturam-se no icônico quando seu caráter simbólico, regido pelas normas, reata antigos vínculos entre a palavra e a imagem, entre o traço do desenho e o traçado da letra. Não se trata mais de uma transcrição da fala e sim de uma proposta formal de dupla orientação, como se observa nos créditos dos produtos cinematográficos e televisuais, como na vinheta de abertura do filme. It's a Mad Mad Mad Mad World.

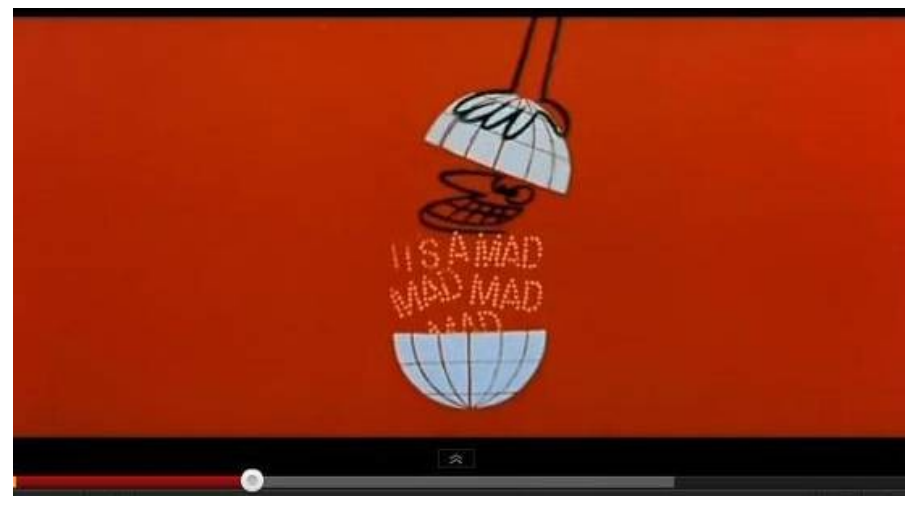

Figura 3 - Frame da abertura de It's a Mad Mad Mad Mad World (1963)

\footnotetext{
${ }^{10}$ Semioticamente, as imagens podem ser relacionadas às categorias sígnicas peirceanas: imagens que imitam o seu objeto (ícones); imagens que o indicam por meio de traços (índices) e imagens que representam por força de uma convenção (símbolos). Qualquer reflexão concernente à distinção entre a imagem e outros tipos de objetos significantes, deve principalmente considerar o que a distingue da sequência de palavras, ou seja, sua iconicidade. Esta similaridade é percebida mesmo no caso de imagens não necessariamente figurativas, "[...] nas três formas de relações entre elementos" (PEIRCE, 1990, p. 58), os chamados hipoícones, a saber: imagens, diagramas e metáforas.
} 


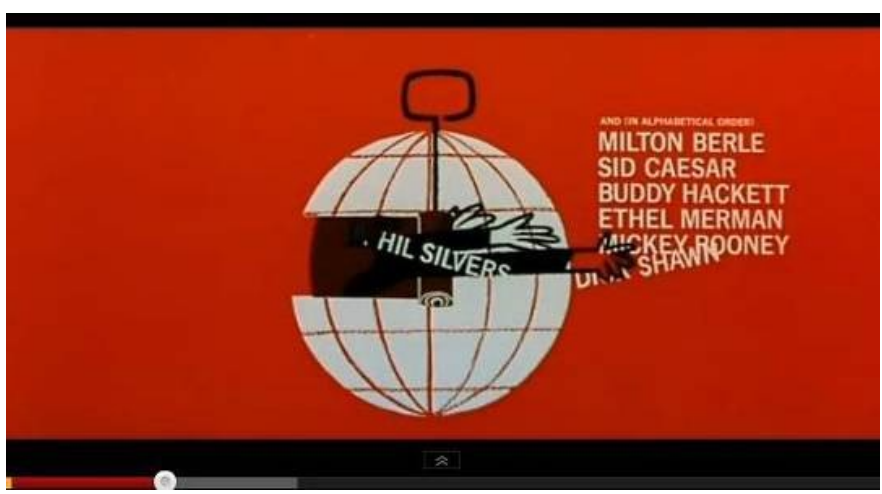

Figura 4- Frame da abertura de It's a Mad Mad Mad Mad World (1963)

$\mathrm{Na}$ tela, as dificuldades apresentadas pelas mais diversas tentativas de se abrir o globo terrestre, para poder mostrar os créditos, obedecem à lógica inverossímil do desenho animado, com seu humor específico. Não se trata apenas de uma ilustração das palavras que compõem os títulos e os créditos do filme, pois as letras estão em movimento e integram construtos icônicos, verbovisuais, que vão muito além da ornamentação. Nesse entrelaçamento de imagens e sentidos sobrepostos é que a vinheta precursora de Bass se aproxima da imagem contemporânea, com seus diagramas de iconicidade dinâmica.

Considero que, valendo-se da reflexão processual sobre as formas canônicas estereotipadas, o artista gráfico foi responsável por uma nova "espécie" de créditos de filmes na década de 1950 e 60. Ao conceber esta vinheta animada para o filme de Stanley Kramer (1963), Bass vai contrapô-la ao discurso cinematográfico, renovando o instrumental, os princípios e as técnicas de seu fazer. Isso faz com que, por força da metalinguagem implícita, esta abertura distancie-se de uma linguagem verbal que é simbólica, segundo Peirce. O verbal satura-se no icônico, manifestando uma recusa das formas convencionais, dos clichês e dos lugares-comuns, próprios da terceiridade peirciana, chegando a impor uma ordem transgressora que lhe permite a afirmação de sua existência, como um sistema metassígnico com suas leis e lógica próprias. Isso significa que os signos icônicos, indiciais e simbólicos são redimensionados por força de uma autocrítica de teor metalinguístico, no próprio projeto da vinheta de Bass. Ela se afirma pela sua diferença, como técnica de animação, em relação ao naturalismo cinematográfico do filme que está apresentando. 


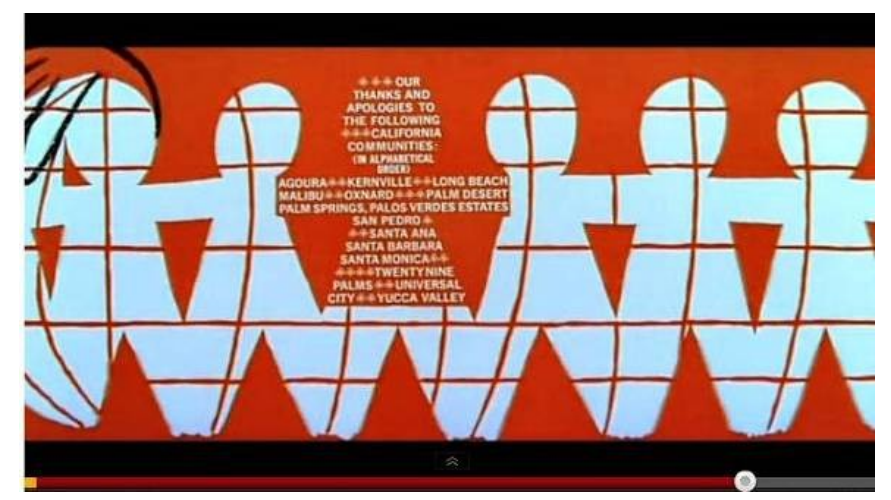

Fig. 5 - Frame da abertura de It's a Mad Mad Mad Mad World (1963)

No contexto da guerra fria dos anos 1960, a interpretação desta peça audiovisual de animação implica em novos sentidos que se agregam aos significados originais, como exemplificado no frame acima, que sugere a paz por meio da alusão a uma brincadeira infantil de recorte em papel dobrado e que, quando aberto, forma um círculo em que todos se dão as mãos.

Em termos de adequação contextual é notável a qualidade da relação intersemiótica alcançada entre os diversos tipos de signos envolvidos no processo de criação desta vinheta. Observo também que as equivalências permitem o preenchimento paradigmático das vigas mestras da respectiva narrativa fílmica, ou seja, levam em consideração a seleção dos temas ou dos seus motivos estruturantes básicos.

\section{Vinhetas contemporâneas e as tecnologias digitais}

Até 1970, as mais expressivas incursões de design gráfico no cinema e na TV eram realizadas em película, utilizando técnicas de animação ${ }^{11}$ convencional e trucagem. Por outro lado, a história da animação digital está diretamente relacionada com a história da computação gráfica, pois, desde o início, foram percebidas suas possibilidades para gerar a ilusão de movimento.

A partir de 1980, com o desenvolvimento da modelagem e da animação 3D, técnicas imediatamente absorvidas pela televisão e pelo cinema, o processo mudou radicalmente. A

\footnotetext{
${ }^{11}$ Animação refere-se ao processo segundo o qual cada fotograma de um filme é produzido individualmente, podendo ser gerado quer por computação gráfica, quer fotografando uma imagem desenhada, quer repetidamente fazendo-se pequenas mudanças em um modelo e fotografando o resultado (claymation e stop motion).
} 
chegada da era digital permitiu combinar e animar livremente camadas de imagem de todo o tipo (vídeo, fotografias e elementos gráficos diversos), juntamente com música, ruídos e efeitos sonoros. O processo é denominado motion graphics e traz, em suas origens, referências ao cinema e ao filme de animação, até chegar à TV e ao vídeo, herdando dessas linguagens algumas das suas convenções, como um conjunto de formas de expressão. Trata-se de uma área de criação que permite combinar e manipular livremente camadas de imagens de todo o tipo, temporalizadas ou não, expressivamente exploradas no chamado broadcast design, ou seja, com aplicações do design gráfico nas vinhetas, spots, aberturas de programas da TV e também no cinema.

Em vinhetas mais recentes, a animação pode combinar o live action aos elementos gráficos bidimensionais, fotografias e outros tipos de imagens, gerando uma visualidade marcada pela colagem, pela fotomontagem, pelas superposições e por uma infinidade de recursos digitais. É o que ocorre, por exemplo, nas aberturas de Casino Royale (2006) e de Juno (2007), com suas opções tecnoestéticas pelo hibridismo, bem diversas daquela observada na obra de Saul Bass, que estava mais próxima do desenho animado tradicional.

\section{Dois exemplos do século XXI}

As tecnologias digitais originam uma topologia diferenciada, que rege a morfogênese e as distribuições das imagens de síntese; imagens essas que, mesmo concebidas a partir de um modelo real, são de fato uma recomposição numérica deste modelo. Como resultado, temse uma potencialidade quase infinita de imagens, capazes de apresentar múltiplas perspectivas e aspectos inéditos de "objetos" em movimento incessante, não mais representá-los. Como já discutido no início deste artigo, o que está em questão é o conceito de mimese associado ao signo indicial peirciano (PEIRCE, 1990), ou seja, aquele definido por sua relação dinâmica causal com seu objeto.

O exposto leva-me a dar prosseguimento às reflexões sobre o tema, com a análise da abertura fílmica criada por Peter Lamont para Casino Royale (2006), dirigido por Martin Campbell. Nesta sequência de abertura do vigésimo primeiro filme de James Bond, percebese que suas raízes encontram-se no motion graphics, no cinema, na TV e nas experiências plásticas de alguns tipos de cinema de animação que procuram se distanciar da representação 
do real (o índice) e da narrativa linear (sintagmática), logicamente organizada. Sua ênfase está no trabalho com os ícones, ou seja, na percepção qualitativa que viabiliza uma nova sintaxe da transformação verbovisual, na qual o dinamismo formal e cromático integra-se às sonoridades.

Trata-se de uma versão modernizada das tradicionais vinhetas de Maurice Binder para os filmes do agente 007, que são verdadeiros videoclipes, com cerca de 3 minutos, trazendo referências ao enredo e à música inesquecível. Todas as famosas aberturas de Binder ${ }^{12}$ seguem uma mesma linha, mas com variações. A imagem inicial do agente atirando em uma mira aperfeiçoou-se ao longo dos anos, acompanhando a evolução das linguagens das novas mídias.
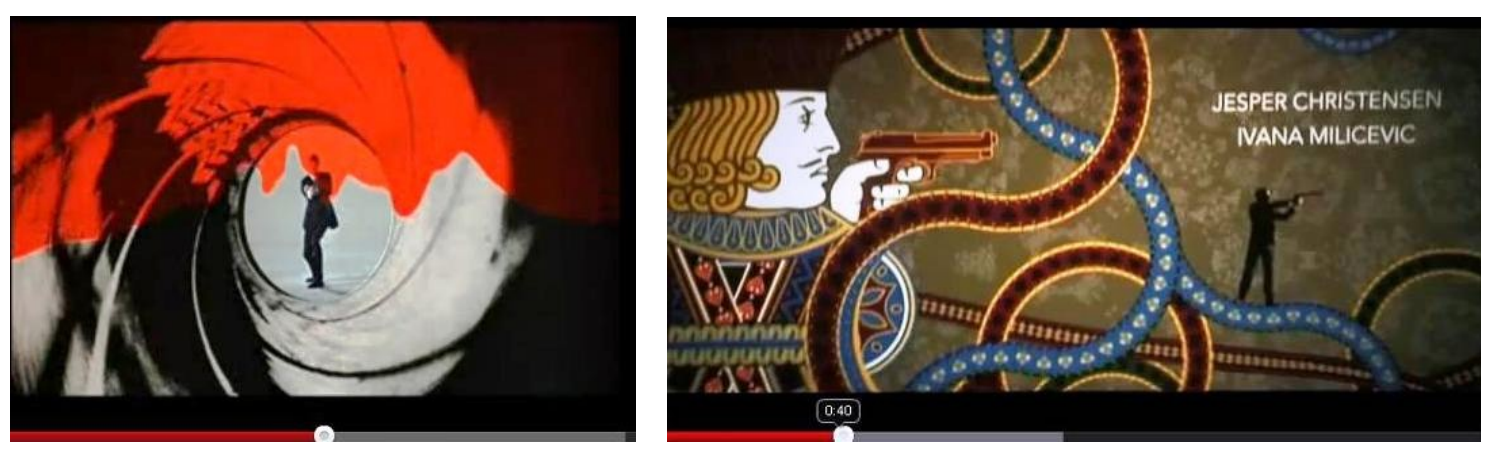

Figuras 6 e 7 - Frames da abertura do filme Casino Royale (2006).

Por outro lado, diante dos dispositivos concebidos para gerar e inserir caracteres de diferentes tamanhos, tipologias e cores, sobrepondo-os ou não, a imagens pré-existentes, julgo que, no geral, a inventividade tem ficado num patamar inferior, quando se trata da tipografia em créditos iniciais de filmes ou de telenovelas. Acredito ser este o caso da abertura criada por Lamont. Também é uma sequência animada, complexa e bem realizada, mas que parece reservar pouca atenção ao design dos signos verbais, como se vê na imagem a seguir.

\footnotetext{
${ }_{12}$ Maurice Binder criou aberturas para os filmes da série durante duas décadas, além de outros trabalhos audiovisuais.
} 


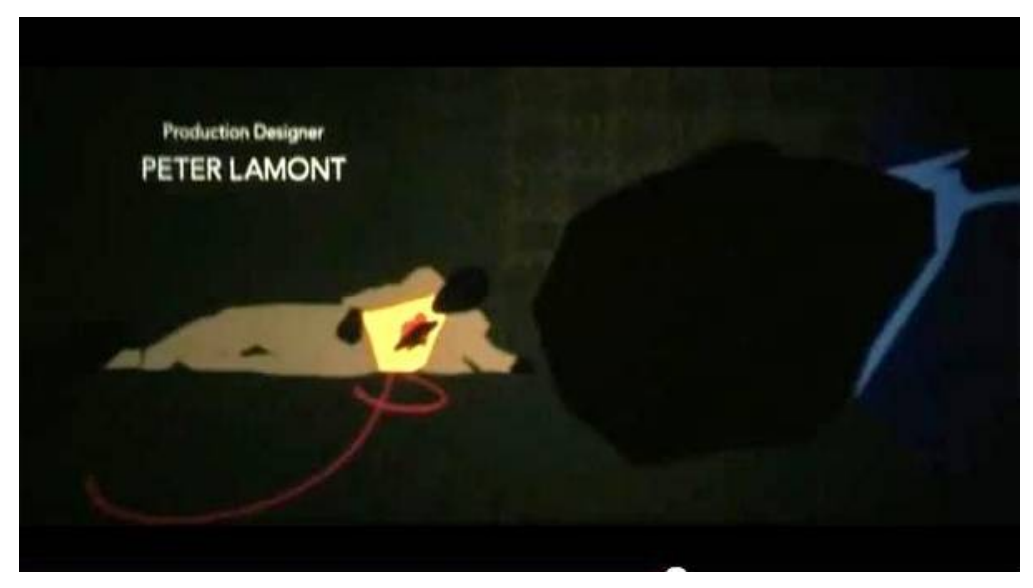

Figura 8 - Frame da abertura do filme Casino Royale (2006).

Nesse sentido, considero a sequência que destaca o tema de cassino, através da ação do personagem em meio a cartas de baralho, como uma das mais icônicas da referida abertura, sendo também uma das únicas em que os tipos gráficos sofrem alterações de acordo com o tom emocional da cena.

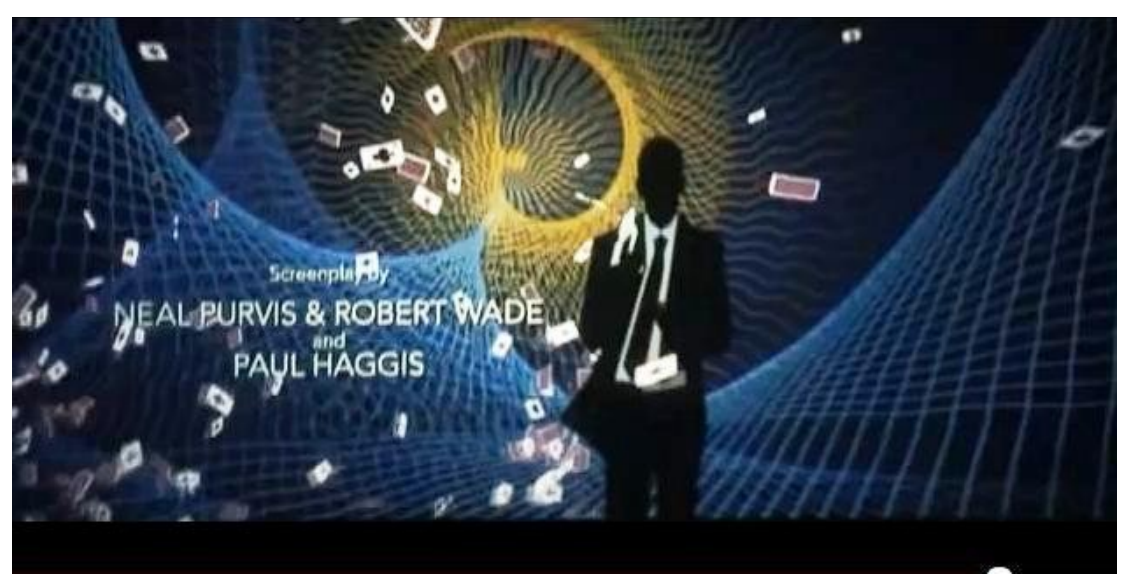

Figura 9 - Frame da abertura do filme Casino Royale (2006).

Apesar da ressalva feita à exploração dos signos verbais na vinheta de Lamont, julgo que sua complexidade elaborativa corrobora os atuais desafios que o estatuto da imagem digital impõe na "sociedade do espetáculo" - conceito criado por Guy Debord no início dos anos 60 - segundo o qual tudo o que era vivido diretamente tornou-se uma representação, uma inversão concreta da vida; ou seja "o movimento autônomo do não vivo [...] uma relação 
social entre pessoas mediada por imagens [...] uma visão do mundo que se objetivou". (DEBORD, 1997, p. 132).

Considero que se trata de um outro tipo de relação mimética, que demanda um redimensionamento dos estudos sobre a representação. Por seu caráter "espetacular" e por seu hibridismo exacerbado, eu diria que a vinheta de Casino Royale estatui-se como um "evento" sinestésico, na acepção mais lata do termo. Para Philadelpho Menezes, a sinestesia,

[...] propugna a intercomunicabilidade das linguagens no mesmo espaço artístico, assimilando uma linha que dos happenings dos anos sessenta chega às performances atuais, fazendo conviver, sobretudo através das formas de espetáculo, os seus signos mais peculiares com os traços, ainda levemente segmentados de outras formas de comunicação. (MENEZES, 1994, p. 211)

Julgo que a referida vinheta consiste numa profusão de imagens e sons, além das palavras escritas superpostas às imagens em constante mutação, em inegável interlocução com a videoarte e com as mudanças radicais na morfogênese e na comunicação das imagens digitais, como assinala Edmond Couchot "[...] tudo se passa então como se a simulação numérica engendrasse a aparição de uma outra dimensão do real, bem diferente de uma cópia, de uma representação ou de uma duplicação: um análogo purificado e transmutado pelo cálculo". (COUCHOT, 2003, p. 173). Segundo o autor, estamos vivendo inegavelmente uma "nova era na história da imagem", pois não se percebe, não se transmite, nem se conserva, muito menos se pensa a imagem como antes.

Por outro lado, na animação elaborada por Steve Saklad, que serve de abertura ao filme Juno (2007) de Jason Reitman, apesar da aparente simplicidade, foram utilizadas cerca de 900 cópias xerox, coloridas a mão, para mostrar a jovem protagonista caminhando pelo bairro. No fundo, porém, seus signos interagentes também inauguram outra semântica, através do processo intersemiótico de montagem entre a letra e a figura animada ou entre a câmera e o desenho. 

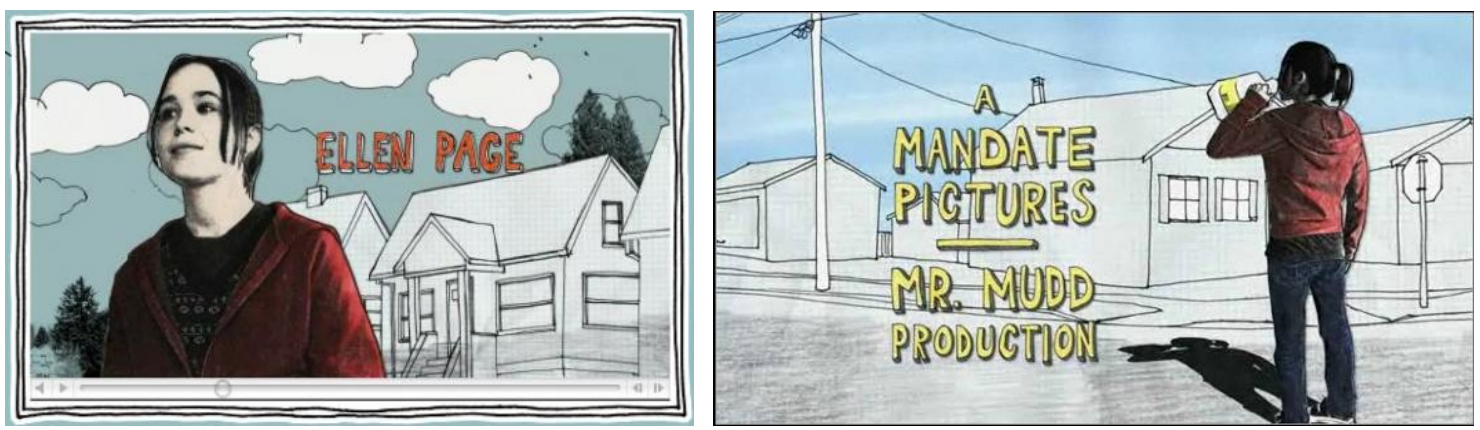

Figura 10 e 11 - Frames da abertura do filme Juno (2007).

O tom ingênuo do filme ${ }^{13}$, que trata da gravidez na adolescência, é reforçado pela canção tema. Trata-se de um filme independente, aclamado pela crítica, escrito pela iniciante Diablo Cody e vencedor do Oscar de melhor roteiro original em 2007.

Em termos de representação, esta vinheta de abertura recusou os códigos imagísticos do cinema naturalista, considerado indicial, de modo a enfatizar os códigos iconográficos das Histórias em Quadrinhos ou até mesmo dos story boards. Trata-se de uma opção estética pela bidimensionalidade das imagens: são casas simplesmente traçadas em preto sobre o branco; um céu verde azulado, com alguns traçados de nuvens e outras nuvens recortadas, deixando ver o fundo branco. A protagonista, na maioria das vezes, é mostrada à direita ou à esquerda da tela, com espaços para os créditos.

Num jogo deliberadamente artificial, o visual inusitado desta sequência decorre de outro tipo de relação mimética, que permite constatar que o objetivo destas imagens não é representar a caminhada da garota como se fosse real, mas sim, pelo contrário, efetuar sua representação como ela seria representada no papel, com todo seu poder expressivo ligado às artes visuais, fundamentalmente icônicas. Trata-se não só da reconsideração do conceito de mimese, mas também da questão da ampliação do acesso a representações e da consequente experiência de saturação de imagens, que muda a percepção em termos qualitativos.

Assim é que, tendo à disposição todas as ferramentas da tecnologia para os efeitos $3 \mathrm{D}$ capazes de criar cenas o mais próximo possível do real, nesta vinheta de abertura, paradoxalmente, opta-se por colocar toda a técnica, não a serviço da recriação da realidade, mas sim a serviço da ficção, optando pela artificialidade como proposta estética. Desse modo, como tudo que foge aos clichês, a abertura do filme provoca um estranhamento, ou seja, altera

\footnotetext{
${ }^{13}$ Diante do excelente resultado, Barry Louis Polisar, cantor da música tema, utilizou a abertura para seu videoclipe.
} 
a duração da percepção e provoca o efeito de singularização do objeto estético, que se afirma por sua originalidade. Isso porque, em lugar da ação e dos efeitos computadorizados alucinantes, viabilizados pela computação gráfica e pelos recursos $3 \mathrm{D}$, a referida sequência inicial parece procurar a estaticidade pictórica. Observam-se enquadramentos metassígnicos pictoriais, basicamente metafóricos, porque são apreendidos pelo espectador a partir de evidências indiretas.

Uma vez que textos estéticos em novos suportes falam simultaneamente com diferentes códigos, o importante é perceber que as significações eclodem do encontro entre os signos. Assim sendo, julgo que a abertura de Juno atinge seu diferencial por seus mecanismos expressivos ou suas estratégias discursivas que integram imagens em movimento aos gestos, palavras, sons, cores e ritmos, num processo intersemiótico de efeitos poéticos.

Acredito que, impregnada pelas formas e códigos específicos de outro meio (a página impressa), a vinheta liberta-se das convenções ou normas, valendo-se de um ambiente tecnológico que lhe oferece as ferramentas mais apropriadas para um redimensionamento do gênero. $O$ filme só inicia quando termina a animação e a jovem passa para o outro plano, aquele do cinema naturalista, com sua proposta de representação da realidade pelo processo fotoquímico, que é indicial em sua essência.

Todavia, percebe-se também nessa abertura uma perfeita simulação do uso da câmera, em enquadramentos sugestivamente icônicos, como nas cenas em que os vocábulos são superpostos ao tênis e parte da calça jeans da jovem ou no momento em que ela olha diretamente para cima (para a câmera) e caminha em direção às palavras escritas na calçada.

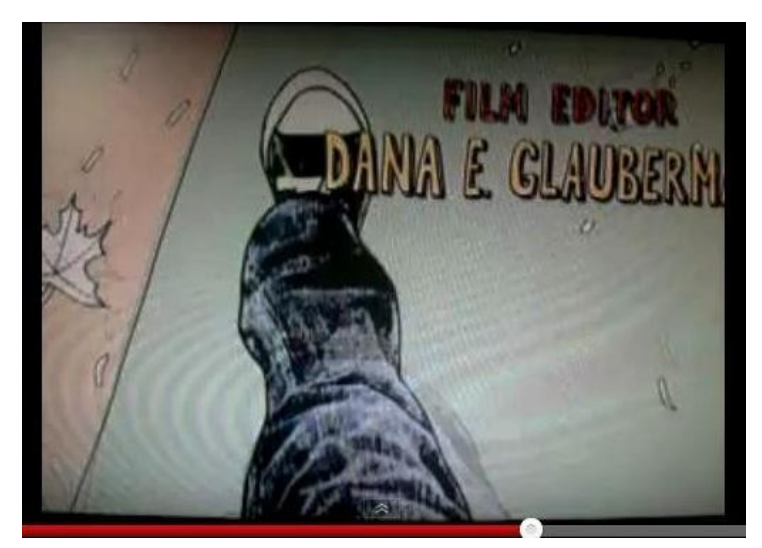

Figura 12 e 13 - Frames da abertura do filme Juno (2007). 
Recursos e efeitos similares já haviam sido utilizados, em outros filmes, como por exemplo, em Corra Lola, Corra (1998), dirigido por Tom Tykwer. Não só na abertura, mas no filme todo, o diretor brinca com as várias linguagens do cinema: desde colagem de fotos até cenas gravadas com filmadora caseira. A corrida de Lola é movida por uma trilha sonora vibrante e movimentos rápidos de câmera mesclados ao desenho animado.

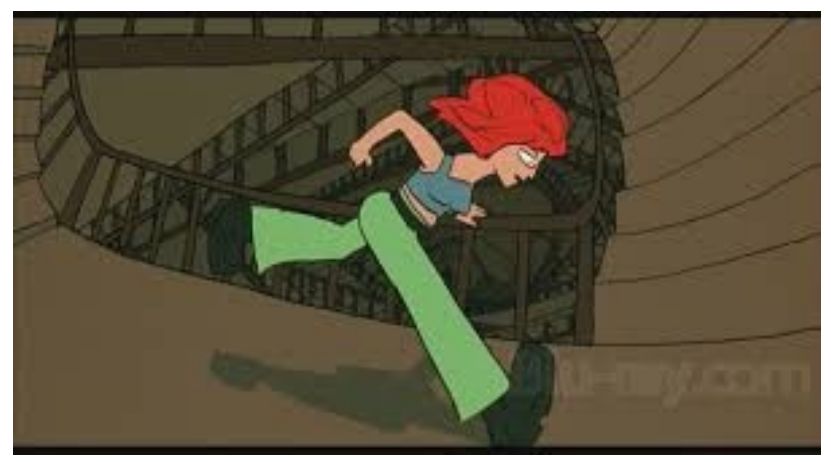

Figura 14 - Frame da abertura do filme Run Lola, Run (1998).

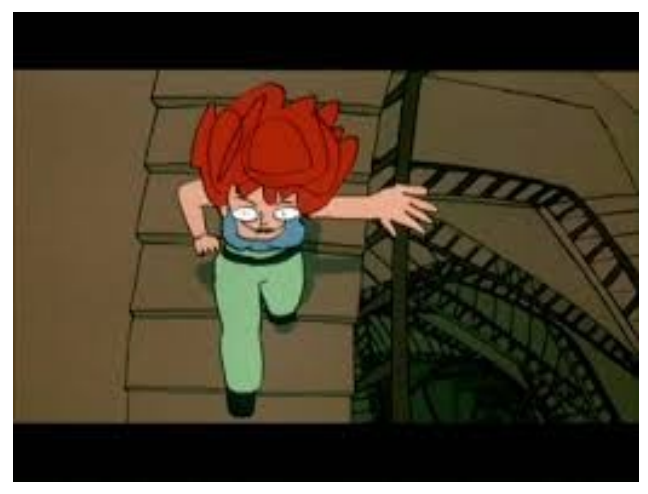

Figura 15- Frame da abertura do filme Run, Lola, Run (1998).

Os exemplos demonstram que a maneira de captar a imagem de forma inusitada, muito usada pela arte fotográfica, acabou também por influenciar o cinema live action e o de animação, na exploração da perspectiva ou na composição da cena e, mais especificamente, no uso das nuances cromáticas. Nesse sentido, a pintura pode ser considerada o agente da passagem entre imagem-cinema e imagem-vídeo, como explica Nelson Brissac Peixoto:

A pintura é a referência principal do cinema contemporâneo. $\mathrm{O}$ arcaico no presente, o artesanal na reprodução técnica, o matérico no cinético. [...] é justamente a partir 
do plano - do movimento e da decupagem supostos nessa noção - que cineastas podem se comparar a pintores. O plano - que pode ser composto, construído, como um quadro - é o que aproxima o cinema da pintura. (PEIXOTO, 1993, p. 246)

Alguns anos depois, percebe-se que, reiterando a idéia de vários textos teóricos que estudam arqueologia das imagens animadas, Manovich vai considerar como ostensiva a relação entre a pintura e o cinema digital, em termos da opção mimética diferenciada viabilizada pelas novas tecnologias.

A oposição entre os estilos da animação e o cinema define a cultura da imagem em movimento no século vinte. A animação salienta seu caráter artificial, admitindo abertamente que suas imagens são meras representações. Sua linguagem visual é mais ligada ao gráfico do que ao fotográfico. (MANOVICH, 2001, p. 298). ${ }^{14}$

O autor enfatiza que, a partir dos anos 1990, graças às novas mídias computadorizadas, a animação deixa de ser uma técnica marginalizada para ocupar lugar central; o que me leva a acreditar que o ato de fazer cinema, hoje, redefine-se por força dos novos princípios do cinema digital. A filmagem live action passa a ser manualmente manipulada: animada, combinada com imagens geradas por computador e retocadas digitalmente. As imagens finais são construídas ou modificadas à mão, a partir de diferentes elementos, como o 3D. Assim como na abertura de Juno, verifica-se um procedimento tecnoestético que remete ao pensamento do referido autor:

\begin{abstract}
A grande vantagem do mapeamento do tempo no espaço 2-D, já presente nos primeiros aparatos cinematográficos de Edison, é agora realizada: pode-se modificar eventos no tempo literalmente pintando sobre uma sequência de frames, tratando-os então como uma simples imagem. (MANOVICH, 2001, p. 255). ${ }^{15}$
\end{abstract}

$\mathrm{Na}$ animação tradicional, também conhecida como animação em células, os desenhos são feitos a mão, e retraçados ou copiados num plástico transparente. Depois, coloca-se a célula sobre um fundo pintado e os movimentos são fotografados um a um com uma câmara.

\footnotetext{
${ }^{14}$ No original: The opposition between the styles of animation and cinema define the culture of the moving image in the twentieth century. Animation foregrounds its artificial character, openly admitting that its images are mere representations. Its visual language is more aligned to the graphic than to the photographic.

${ }^{15}$ No original: The full advantage of mapping time into 2-D space, already present in Edison's first cinema apparatus is now realized: one can modify events in time by literally painting on a sequence of frames, treating them as a single image.
} 
Embora o uso de células e de câmeras esteja em declínio devido ao avanço e vantagens da

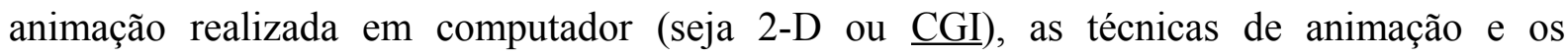
personagens clássicos ainda servem de inspiração para as novas gerações de animadores. Já no suporte de materialização da mídia eletrônica, os campos podem ser trabalhados de maneira sincrônica ou assincrônica, uma vez que a idéia de cada vinheta, diferentemente de uma mera criação de animação de textos, está sendo pensada de modo que se possa vir a explorar a integração motivada de todos os seus fragmentos.

\section{Ponderações finais}

Distanciando-se da cinematografia tradicional, em cada uma das vinhetas abordadas, percebe-se uma diferente opção pelo artificialismo e pela bidimensionalidade do desenho, o que fica mais óbvio na animação de Saul Bass. Destarte, nas duas outras aberturas analisadas, embora resultantes de processos diversificados, os cenários, a caminhada da jovem protagonista ou as ações do agente 007, tudo é propositalmente anti-naturalista, porque as mídias digitais possibilitam que as já existentes se reorganizem de novas maneiras, redimensionando seu potencial expressivo em termos indiciais e icônicos.

Assim como as imagens são reformatadas pela saturação em outro suporte, também a linguagem escrita é manipulada, em sua morfogênese, pela força inusitada das possibilidades viabilizadas pela computação gráfica. Nas últimas décadas, após o advento do gerador de caracteres, novos softwares permitem uma infinidade de manipulações nas letras, palavras ou textos inteiros, nos prólogos de obras cinematográficas. Tais intervenções permitem o redimensionamento dos textos audiovisuais, por meio das negociações tecnoestéticas entre as imagens e as sonoridades expressivas. O resultado são efeitos impactantes e memoráveis, que garantem a prevalência de relações intersticiais responsáveis pela ampliação do espaço da escrita/escritura nas telas dos mais diferentes tamanhos.

\section{Referências}

AZNAR, Sidney Carlos. Vinheta: do pergaminho ao vídeo. São Paulo: Arte \& Ciência/ UNIMAR, 1997. 
BROWN, William. Supercinema. Film - philosopy for the digital age. New York- Oxford: Berghahh, 2015.

COUCHOT, Edmond. A Tecnologia na Arte: da fotografia à realidade virtual. Porto Alegre: Editora da UFRGS, 2003.

DEBORD, Guy. A Sociedade do Espetáculo. Rio de Janeiro: Contraponto, 1997.

GRAÇA, Marina Estela. Entre a Palavra e o Gesto. Elementos para uma poética da imagem animada. São Paulo: Ed. Senac, 2006.

MANOVICH, Lev. The Language of New Media. Cambridge: The MIT Press, 2001.

MENEZES, Philadelpho. A Crise do Passado. São Paulo: Experimento, 1994.

PEIRCE, Charles Sanders. Semiótica. São Paulo: Perspectiva, 1990.

PEIXOTO, Nelson Brissac. "Passagens da Imagem: Pintura, Fotografia, Cinema, Arquitetura." In. PARENTE, André. Org. Imagem-Máquina: a era das tecnologias do virtual. Rio de Janeiro: Ed. 34, 1993. p. 237-252.

PIGNATARI, Décio Informação. Linguagem. Comunicação. São Paulo: Perspectiva, 1971.

SADOUL, George. História Del Cine. Buenos Aires: Ediciones Losange, 1956.

SAUSSURE, Ferdinand de. Curso de Linguística Geral. São Paulo: Editora Cultrix, 1971. 